\title{
"First Aid for Scalds" campaign: reaching Sydney's Chinese, Vietnamese, and Arabic speaking communities
}

\author{
Lesley King, Margaret Thomas, Kristen Gatenby, Angela Georgiou, Myna Hua
}

\begin{abstract}
Objectives-As a serious yet preventable problem, scald injuries in children have been a priority for prevention in Australia and other developed countries. Not only can the occurrence of scalds be prevented, but immediate first aid treatment offers an effective method for secondary prevention, reducing the severity of scalds. Despite the success of scald prevention initiatives, local evidence suggested that first aid knowledge was lacking in some minority ethnic groups. To redress this gap, the "First Aid for Scalds" campaign for those from a non-English speaking background was specifically targeted to three ethnic groups (Vietnamese, Chinese, and Arabic), with the aim of increasing the proportions of parents and caregivers who had correct knowledge of first aid treatment for scalds. The primary strategy was a media campaign, including advertisements on ethnic radio and in ethnic newspapers.
\end{abstract}

Methods-The evaluation design included formative research and impact evaluation. The impact evaluation study involved random population based telephone surveys with each of the three language groups, before and after the campaign, to assess the reach and effectiveness of the campaign.

Results-After the campaign, there were significant increases in the proportion of people who knew the correct first aid treatment for scalds. There were substantial variations in campaign recall and knowledge between each of the three language groups. The largest improvement was found in the Vietnamese group. Conclusion-The association between campaign recall and increase in correct knowledge, and the absence of any similar interventions during the campaign period, give credence to the conclusion that the changes observed were a result of the campaign. The results demonstrate the value of community based injury prevention campaigns specifically targeting linguistically diverse communities.

(Injury Prevention 1999;5:104-108)

Keywords: scald prevention; multicultural health promotion; media campaign

Scald injuries are a serious problem for young children. They are the most common type of burn injury to children under 5 years old, and although mortality from them is low, many scalds require a long hospital stay. ${ }^{1}$ Due to the serious nature of these injuries, the physical and emotional effects on children and their caregivers can be enormous.

Data from the New South Wales (NSW) Hospital Inpatients Collection showed that in the period 1993-94, 445 children under 5 years were admitted to hospitals because of a scald injury. In 1994-95 the figure dropped to 401 , possibly due to the effects of prevention campaigns conducted in NSW. In 1996, Nguyen found that, between 1991 and 1995, $33 \%$ of children admitted to Sydney's Royal Alexandra Hospital for Children, came from families of a non-English speaking background. ${ }^{2}$ This supports 1990-91 data from the NSW Childsafe surveillance system that showed at least $37 \%$ of children admitted to emergency services in participating paediatric hospitals came from homes where a language other than English was spoken. ${ }^{3}$ The highest numbers were from families speaking Vietnamese, Chinese, and Arabic languages.

Strategies for preventing scalds

As a serious yet preventable problem, scalds have been a priority for primary prevention in Australia and other developed countries. ${ }^{4-9}$ In addition, secondary prevention in the form of appropriate first aid has been shown to be feasible and effective in reducing the severity of scald injuries..$^{11}$ The key first aid step is applying cool running water for at least 30 minutes. ${ }^{11}$ Because the majority of scalds sustained by children are in the home, the application of first aid by parents and caregivers is a feasible and potentially significant contribution to reducing the severity of scald injuries. ${ }^{10}$

Reaching ethnic minorities

English language mass media campaigns have been found to have limited reach and recall in groups with a non-English speaking background, who comprise almost one third of the population of Sydney. ${ }^{12}{ }^{13}$ However, culturally appropriate and specifically targeted campaigns in community languages have been found to be effective in reaching their target groups. ${ }^{121415}$ For example, the Greek "Good Heart, Good Life" campaign was most effective in reaching people with poor English proficiency, who were not aware of English language campaigns. ${ }^{12}$ 
Multicultural radio (community and government sponsored), television, multicultural print, translated materials, community networks, and families and friends have all been identified as significant information pathways for people from non-English speaking backgrounds. ${ }^{13}$

\section{Rationale for the First Aid for Scalds campaign for those from non-English speaking backgrounds}

The need for specifically targeted campaigns in community languages on scald prevention was confirmed in local research with groups from non-English speaking backgrounds. ${ }^{16}$ Previous programs had emphasised general awareness of risks and adoption of environmental interventions, such as installing child resistant taps and lowering hot water temperature, with information on first aid included in a brochure. However, focus group discussions with Vietnamese and Arabic groups indicated that information on adjusting the temperature of hot water systems was not easily understood or relevant. ${ }^{16}$ Newly arrived groups of people from non-English speaking backgrounds, with poor English proficiency, found it difficult to negotiate with landlords on fixed modifications to plumbing systems, and had not been able to obtain the recommended portable safety devices, such as childsafe tap covers. ${ }^{17}{ }^{18}$ The focus groups conducted with Vietnamese and Arabic mothers also indicated that there was a lot of misinformation about the most appropriate first aid treatment for scalds. ${ }^{16}$ Consultations with parents of children who had incurred a scald, conducted as part of the development of the NSW statewide campaign, found that these parents wished that they had better first aid knowledge at the time. ${ }^{17}$

On the strength of the information about the prevalence of scalds, the seriousness and preventability of the problem, the relevance and potential impact of correct first aid, and the limitations of previous campaigns in reach- ing and influencing large groups from nonEnglish speaking backgrounds, the "First Aid for Scalds" campaign was developed. Vietnamese, Chinese, and Arabic communities comprise three of the largest of these groups, with a high proportion of families with young children, living in Sydney.

\section{Methods}

CAMPAIGN DESCRIPTION

The campaign aimed to increase the proportion of Vietnamese, Chinese, and Arabic parents and caregivers living in Sydney who had correct knowledge of first aid treatment for scalds.

The development stage involved exploring target groups' beliefs and practices about scalds, to guide the design of images and messages for communication materials, and ensure cultural relevance. At a later stage, formative research was conducted to test the relevance, comprehension, and appeal of all communication materials before they were finalised.

A media campaign was the primary strategy. It included advertisements on the Special Broadcasting Service (SBS) radio and in ethnic newspapers. The media mix recognised the relative strengths of radio and print strategies, as radio is particularly effective in reaching large numbers of people, and translated print material is most useful when it provides action oriented information and does not rely on high literacy levels. ${ }^{13}$

Radio advertisements were played five times a week for four weeks on Vietnamese, Cantonese, and Arabic programs and twice a week for four weeks on the Mandarin program. Newspaper advertisements were placed twice a week for four weeks in each of five newspapers. The media strategy included press releases, coverage in a regular health column in ethnic newspapers, radio interviews with community representatives, and, through a key Chinese organisation, a Chinese media conference.

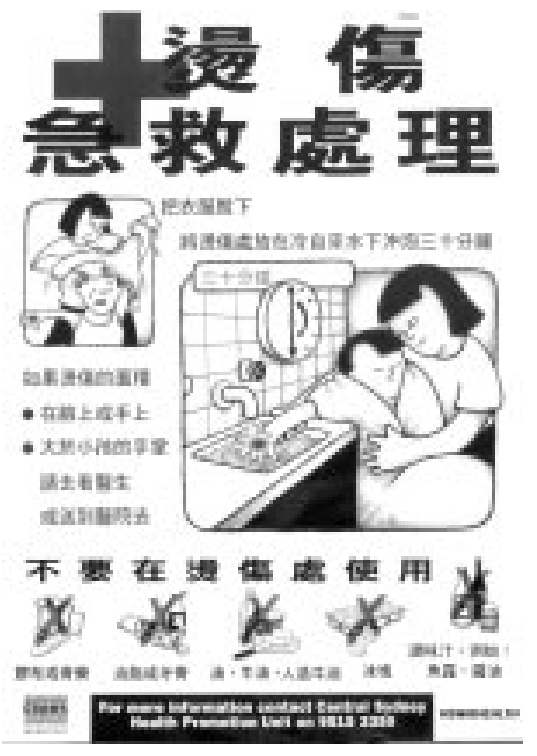

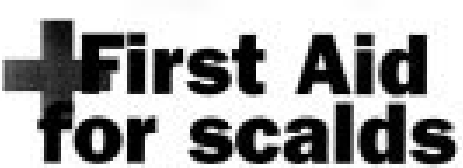
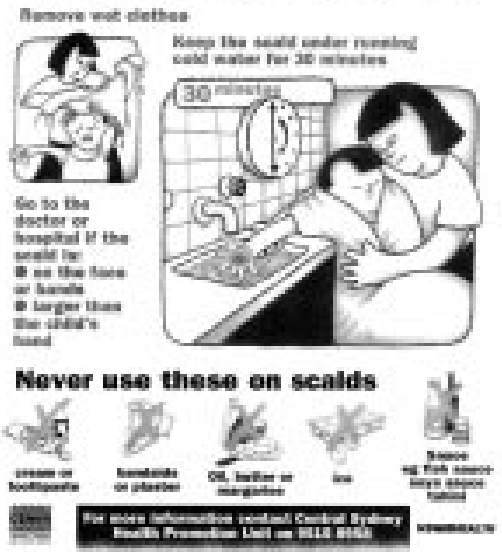
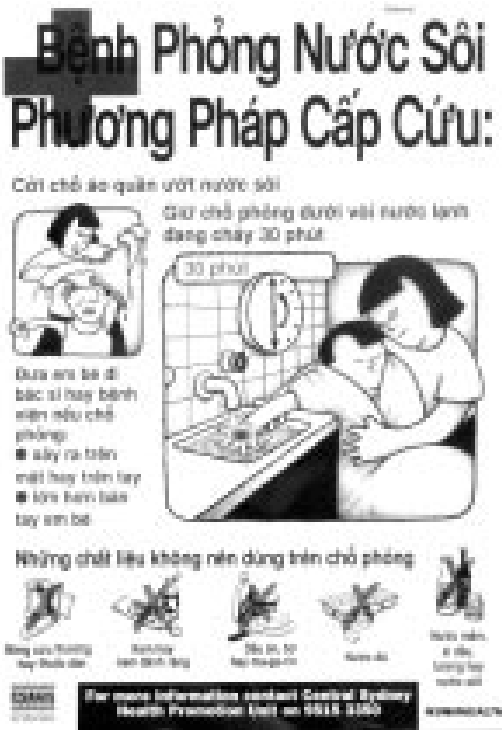

Figure 1 Leaflets in Chinese, English, and Vietnamese. 
The print resources comprised posters and smaller fliers. Advertisements and posters contained information about correct first aid treatment and pointed out common incorrect treatments, such as tahini in the Arabic community and soya sauce and fish sauce in Vietnamese and Chinese communities. The message aimed to catch the attention of the target groups, challenge their existing beliefs and practices, and introduce new information. The print resources comprised visual images that could stand on their own, without written text (see fig 1). The newspaper advertisements were a small version of the poster, and the radio advertisements were based on the written message of the poster, with the phone number of a community organisation given for those seeking further information. The communication approach was simply informational, and designed to be appropriate for a wide audience, including people with low literacy levels.

The campaign involved substantial consultation with community and ethnic organisations, which supported the work by distributing posters and pamphlets. Representatives of these organisations were provided with information and training around the issue of scald prevention and first aid treatment. Pamphlets and posters were also distributed through general practitioner clinics. These print materials were distributed through over 500 locations. A total of 1500 posters in each language were produced, as well as 10000 fliers in Arabic and Vietnamese and 20000 in Chinese.

\section{IMPACT EVALUATION}

The impact of the campaign was evaluated by telephone surveys with each of the three target population groups, conducted during the two weeks before and two to three weeks after the conclusion of the campaign. The questionnaire contained items on campaign recall, experience of scalds, knowledge of correct first aid steps, when to seek medical attention, and basic demographic information. It was translated into Arabic, Vietnamese, and Chinese languages by professional, accredited translators.

For the telephone surveys, households in the Sydney metropolitan region were randomly selected from specially constructed databases, using an electronic version of the Sydney residential telephone directory and lists of common Vietnamese, Chinese, and Arabic surnames. The lists of surnames were compiled by ethnic community workers and independently verified. The relative advantages and accuracy of this method of sample selection has been established in an independent study. ${ }^{18}$ Individual respondents were selected from households if they had children under the age of 5 years, or they cared for children less than 5 on at least one day per month. Telephone calls were made in the late afternoon and early evening, and up to five call-backs were made at different times, if the number was unanswered or a suitable person was not available. Independent bilingual interviewers, who were trained to follow a standard protocol, conducted all interviews. Responses to knowledge questions were recorded in full and later coded.
Answers were coded as correct when the respondent named at least two of four instructions contained in the campaign message, such as use cold running water, remove wet clothes.

In addition to the telephone survey, three focus groups were conducted, one with each of the target groups, after the post-campaign survey.

\section{STATISTICAL ANALYSIS}

Data from the surveys before and after the campaign were analysed using the software packages Epi-Info (version 6) ${ }^{19}$ and SPSS. ${ }^{20} \chi^{2}$ statistics for differences in proportion between the two surveys were calculated for the major variables of interest, such as campaign recall and knowledge of correct first aid treatment. Comparisons between the three language groups for these variables were also made. To check for any substantial differences in potential confounders between the surveys, $\chi^{2}$ statistics were used to compare demographic variables.

\section{Results}

RESPONSE RATE

Of the calls made to target households $80.8 \%$ were conducted successfully. A large proportion of calls $(77 \%)$ reached homes that were not members of the target groups.

CHARACTERISTICS OF THE SAMPLE

There were no significant differences in proportions between survey samples before and after the campaign for gender, country of birth, and level of education. There were differences between language groups in a number of demographic variables, including levels of education, number of children in household, and proportion born in Australia, with the Arabic group containing significantly more Australian born residents than the other two. Almost $40 \%$ of Arabic interviewees completed the survey in English, compared with less than $5 \%$ of the Chinese and Vietnamese samples. Sample sizes are noted in table 1.

\section{CAMPAIGN RECALI}

When asked whether they had heard of the "First Aid for Scalds" campaign, 39.6\% of the survey sample after the campaign stated they had, compared with $8.5 \%$ before the campaign $\left(\chi^{2}=75.07, \mathrm{p}<0.0001\right)$.

There were substantial variations in recall between each of the three language groups, as shown in table 1 . The Vietnamese group most frequently reported hearing about the scald campaign (from $4 \%$ before to $63 \%$ after).

Table 1 Percentage of respondents recalling the campaign when prompted (before and after for each language group)

\begin{tabular}{lll}
\hline & Before (\%) & After (\%) \\
\hline Arabic & 20.9 & 26.0 \\
& $n=66$ & $n=96$ \\
Chinese $^{\star}$ & 4.2 & 29.9 \\
Vietnamese $^{\star}$ & $n=97$ & $n=107$ \\
& 4.4 & 63.0 \\
& $n=93$ & $n=98$
\end{tabular}

* Statistically significant difference between before and after survey proportions, $\mathrm{p}<0.001$. 
Table 2 Percentages of target groups with correct knowledge of first aid, by exposure to scalds campaign

\begin{tabular}{llll}
\hline & $\begin{array}{l}\text { After }(n=183): \text { of those } \\
\text { who had not heard the } \\
\text { campaign, correct first } \\
\text { aid (\%) }\end{array}$ & $\begin{array}{l}\text { After (n=119): of those } \\
\text { who heard the campaign, } \\
\text { correct first aid (\%) }\end{array}$ \\
\hline first aid (\%) & 70 & 75 \\
Arabic & 62 & 49 & 87 \\
Vietnamese $^{\star}$ & 23 & 36 & 72 \\
\hline
\end{tabular}

${ }^{\star}$ Indicates significant difference between those who heard the campaign and those who did not, $\mathrm{p}<0.0001$.

KNOWLEDGE OF CORRECT FIRST AID

There was a significant change between the two surveys in the proportion of people who reported correct knowledge of first aid, from $41.7 \%$ to $63.2 \% \quad\left(\chi^{2}=25.7, \mathrm{p}<0.0001\right)$. Although there were increases for all groups in knowledge of correct first aid after the campaign, the largest increase was in the Vietnamese group. The percentages of correct responses are shown in table 2. A high proportion of Chinese caregivers who heard the campaign also had correct knowledge of first aid. The Arabic group had comparatively high knowledge before, as well as after, the campaign.

REACH OF CAMPAIGN STRATEGIES

For the Arabic and Vietnamese groups, the most common place where they heard about the campaign was through SBS radio (44\% and $67 \%$, respectively). For the Chinese group, the most common source of exposure was through a Chinese language newspaper (50\%). Overall, $50 \%$ of respondents heard of the campaign through SBS radio, and $15 \%$ of respondents stated that they had heard of the campaign through their local general practitioner.

POST-CAMPAIGN FOCUS GROUP RESULTS

The information from focus groups confirmed the survey results. Focus group participants mentioned seeing and hearing the campaign through all the venues of distribution channels. Some people commented that the posters and pamphlets were particularly useful as references.

\section{Discussion}

The campaign was successful in achieving its goal. It increased all groups' knowledge about the correct first aid treatment for scalds, and this increase was greatest in the Vietnamese community.

The evaluation design, which included formative research, a pre-post impact evaluation study, and post-campaign qualitative research, was appropriate to the scale and nature of the campaign. While a larger sample size and control group would have strengthened the evaluation study, this was not possible for financial and logistic reasons. Despite these limitations, the association between campaign recall and increase in correct knowledge and the absence of any similar interventions during the campaign period, give credence to the conclusion that the changes observed were a result of the campaign.
The design was predicated on the idea that if parents and caregivers know the correct first aid steps, the health outcomes will be lessened severity of burn injuries, therefore avoiding hospitalisation or reducing length of stay. As the annual number of scalds requiring hospitalisation in these target groups is low, evaluation of these outcomes is not appropriate or feasible.

The pattern of association between message exposure and correct knowledge was most evident in the results for the Vietnamese community, and this finding reinforces the importance of achieving maximum exposure. ${ }^{21}$ The relatively lower recall by the Chinese group suggests that further investigation into other media for reaching the target group is required. However, a high proportion of those recalling the campaign acquired the knowledge of first aid, showing that once exposed to the campaign, the message was effectively conveyed.

The Arabic speaking group had a high initial level of knowledge, roughly the same as found in the English speaking population, suggesting there was not much room for improvement. As English speaking, Australian born respondents, many of the Arabic parents were likely to have been exposed to English messages, and less likely to see the Arabic language campaign.

The results support the value of using a variety of media, including radio, newspapers, and posters. While SBS radio was the most effective source of information, many articles were written in the Chinese press as a result of the media conference, and the evaluation showed that this publicity was remembered by Chinese parents.

\section{Implications for prevention}

The results indicate that it is worthwhile to conduct campaigns specifically targeted to ethnic communities. A companion study also shows that this campaign was cost effective and inexpensive to implement (unpublished data). However, the variations in results between the groups caution us that there are significantly different starting points for different groups. We must cater to each according to its situation.

Given the success of this program, the importance of the information for new parents, and the ever changing cohort of parents of $0-5$ year olds forming the target group, repeated implementation is warranted. This would also provide an opportunity to improve the reach of the campaign into the local Chinese community and make other adjustments. However, given the characteristics of the Arabic community in Sydney, a repeat campaign is not recommended. There are many, smaller, newly arrived groups from non-English speaking backgrounds with significant numbers of young children in Sydney (Korean, for example) who would be considered more appropriate target groups.

This initiative provides a model of how community based injury prevention can target several language groups, with adjustments in messages and media according to cultural differences. It illustrates the success of this 
approach, as well as the significant variability between groups. The results indicate that this approach should be disseminated to other localities with large numbers of culturally and linguistically diverse groups, and where scald injuries are a significant problem.

The "First Aid for Scalds" campaign for people from non-English speaking backgrounds was funded by NSW Health. We would like to acknowledge the contribution of a large number of staff from the Central Sydney Division of Population Health, including Jeni Bindon, Xuan Duong, Suzanne Gleeson, Sanaa Guirguis, Mi Ling Wen.

1 Elkington J, Lyle D, Jones J, et al, eds. Scalds in children. Injury Issues 1992;6:1-2. Sydney: NSW Health.

2 Nguyen T. Cultural influences in the initial care of paediatric burn wounds administered by parents. Australia and New Zealand Burn Association Bulletin 1997;20:11-13.

3 NSW Health. Childsafe NSW surveillance system, 1990-1991. Sydney: NSW Health.

4 Overview of Australian State and Territory initiatives to reduce the incidence and severity of scalds. URL: http://www.nisu.flinders.edu.au/pubs/monitor7/ mon7p19.html

5 Carey V, McNeil R. Scalds in children. Australian fournal of Early Childhood 1992;17(3):25-9.

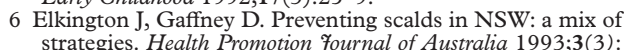
strategies.

7 McLoughlin E, Vince C, Lee AM. Project Burn Prevention: outcome and implications. Am F Public Health 1982;72: $241-7$

8 MacKay AM, Rothman KJ. The incidence and severity of burn injuries following Project Burn Prevention. Am F Public Health 1982;72:248-52.

9 Colver AF, Hutchinson PJ, Judson EC. Promoting children's home safety. BMF 1982;285:1177-80.
10 Davies JWL. Prompt cooling of burned areas: a review of benefits and effector mechanisms. Burns 1982;9:1-6.

11 Australia and New Zealand Burn Association. Emergency management of severe burns (EMSB) course manual. Sydney: Australia and New Zealand Burn Association, 1996.

12 Culpin A, Gleeson S, Thomas M, et al. Evaluation of the "Good Heart, Good Life" project: a three-year campaign to reduce smoking among the Greek community of Sydney's inner west. Health Promotion fournal of Australia 1996;6(2): 44-9.

13 Meiser B, Gurr R. Non-English-speaking persons' perceptions of mental illness and associated information needs: an exploratory study of the Arabic-, Greek-, and Italianexploratory study of the Arabic-, Greek-, and Italian-

tion fournal of Australia 1996;6(3):44-9.

Pham TM. Evaluation of the radio scripts: health is gold. Unpublished report.) Sydney: South Western Sydney Area Health Service, 1995.

15 Roads and Traffic Authority. NESB child restraints campaign report: cultural perspectives. Sydney: Roads and Traffic Authority, May 1996.

16 Health Promotion Unit, Central Sydney Area Health Service. Preventing scalds in Australian children from non-English speaking backgrounds: evaluation of the 1994 scalds campaign. (Unpublished report.) Sydney: Central Sydney Area Health Service, 1995.

17 Georgiou A, Gatenby K. First aid for scalds campaign for NSW's Chinese, Vietnamese and Arabic communities. (Unpublished report.) Sydney: Health Promotion Unit, Central Sydney Area Health Service, 1997.

18 Rissel C, Jorm L, Ward J. Representativeness of three sampling strategies in ethnic health research. Asia-Pacific fournal of Public Health (in press)

19 Dean A, Dean J, Coulumbier D. Epi-Info version 6: a word processing, database and statistics program for epidemiology on microcomputers. Atlanta: Centers for Disease Control and Prevention, 1994

20 SPSS. Advanced statistics 6.1. Chicago: SPSS Inc, 1994.

1 Preston M., Baranowski T, Higginbotham J. Orchestrating the points of community intervention: enhancing the diffusion process. International Quarterly of Community Health Education 1988;9:11-34.

\section{Alcoholic popsicles to debut in Australia; parents voice concerns}

Plans by an Australian company to sell alcoholic popsicles received a frosty reception from parents and others who claimed the target market for the treats included children. The company, however, denied the claims, saying its flavoured ice-on-a-stick would only be available in venues licensed to sell liquor. The amount of alcohol contained in the popsicles is higher than Australia's full strength beers, which typically have an alcohol content of about $4-5 \%$ (contributed by Les Fisher).

\section{Boy who played with hair dryer died in cot blaze}

A 20 month old baby from South Wales died after reaching through the bars of his cot, getting hold of the hair dryer, and switching it on. The inquest heard that the hair dryer had been left plugged in to stop him poking his fingers in the electric socket. The coroner said: "These were a tragic and unfortunate combination of circumstances for which nobody can be blamed" (Daily Telegraph (London), November 1998).

Editor's note: Was the coroner being kind to the family or did he really believe this?

\section{"Plant" signs removed}

Britain's 17000 lollipops - the signs used by school crossing patrol attendants - are being changed so that instead of saying children (outside Wales) and plant (the Welsh for children, in Wales) they will simply carry a graphic showing two children crossing the road. It was felt that the signs may be confusing for motorists who are not bilingual.

Editor's note: Not many of you will be Welsh speakers and even fewer of you are probably monoglot Welsh speakers so this item may not be of too much interest to you. It is here as the Associate Editor who looks after these fillers is Welsh (although he does not speak the language). It was spotted in a British newspaper, the Daily Mail, by one of his colleagues, Rosie Mercer. 